\title{
The treatment of periodontal disease using local oxygen-ozone
}

\author{
Gianluca Sacco, Guglielmo Campus \\ Department of Surgery, Microsurgery and Medicine Sciences, School of Dentistry, University of \\ Sassari, Sassari, Italy
}

\begin{abstract}
The objective was to clinically and microbiologically evaluate local oxygen-ozone therapy used in combination with traditional mechanical therapy versus the use of mechanical therapy alone in a group of patients with periodontal disease. To date, this study is the most representative investigation in the scientific literature as it has the largest sample (113 patients). The project was fully completed in the planning phase, the experimental research stage, the statistical analysis phase and the scientific article draft phase. The results of the study showed a sharp reduction in the clinical-microbiological parameters measured for both study groups. In particular, subjects in the group treated with oxygen-ozone therapy plus mechanical therapy showed a more marked improvement. Although it is possible to observe a general trend of improvement in oral hygiene in Western countries, periodontal health remains a goal yet to be achieved in many subjects. In Italy, roughly $60 \%$ of the population suffers from periodontal disease (from mild to severe) and roughly $10-14 \%$ exhibit fairly advanced forms. The latter group increases dramatically in the age group between 35 and 44 years. The main objective of the clinician who is faced with a patient with periodontal disease is to adopt an appropriate therapeutic approach to halt the progression of the disease and to prevent or reduce the occurrence of any relapses. Mechanical causal therapy is the treatment of choice. However, due to the early recolonization of periodontal pockets by bacteria, various studies are underway in order to find a valid aid to mechanical therapy. In this regard, oxygenozone therapy may be an economic, non-invasive and easy method to implement in the clinical management of the patient with periodontal
\end{abstract}

Correspondence: Gianluca Sacco, Department of Surgery, Microsurgery and Medicine Sciences, School of Dentistry, University of Sassari, viale San Pietro 43/C, 07100 Sassari, Italy.

E-mail: gsacco@uniss.it

Key words: Periodontal pathology; Ozone therapy; Mechanical therapy.

Received for publication: 16 November 2016.

Accepted for publication: 19 December 2016.

(C) Copyright G. Sacco and G. Campus, 2016

Licensee PAGEPress, Italy

Ozone Therapy 2016; 1:6498

doi:10.4081/ozone.2016.6498

This article is distributed under the terms of the Creative Commons Attribution Noncommercial License (by-nc 4.0) which permits any noncommercial use, distribution, and reproduction in any medium, provided the original author(s) and source are credited. disease. One immediate application is the opportunity to use the treatment in selected patients, such as those who present a recurrence of the disease. For example, systemic antibiotic therapy could be replaced with local oxygen-ozone therapy in patients with periodontal abscess. However, additional longitudinal studies are needed to assess any exact range, timing and method of application.

\section{Introduction}

Periodontal disease (PD) is a chronic infectious-inflammatory disease with a multifactorial cyclic evolution, characterized by the destruction of the fibers of the periodontal ligament, resulting in the formation of pockets, apical migration of the junctional epithelium, alveolar bone loss and, in the more advanced stages, marked mobility eventually leading to tooth loss due to lack of support.

Elevated levels of anaerobic bacteria specific to PD and present in dental plaque, such as Aggregatibacter actinomycetemcomitans, Porphyromonas gingivalis, Tannerella forsythia, Prevotella intermedia, Treponema denticola and Fusobacterium nucleatum, are the primary etiologic factor in PD.,2 In fact, it is now known that the tissue destruction observed in PD is the result of the damaging effect of the host immune response to the action of pathogenic bacteria. ${ }^{3}$

Eliminating or at least reducing the loads of these bacterial pathogens is the primary purpose of PD treatment.

Mechanical periodontal therapy (MPT) is the treatment of choice for periodontal diseases, and is defined as the gold standard therapy against which other therapies are compared to prove their effectiveness. ${ }^{4-10}$ Numerous studies have shown the beneficial effects of this treatment both from a clinical point of view and from a microbiological point of view. ${ }^{11-16}$ MPT is able to remove the supra- and subgingival bacterial plaque and tartar deposits attached to the surface of the tooth. ${ }^{17,18}$ Clinically, this means a reduction in probing depth and the bleeding on probing index. ${ }^{14-16}$ Numerous clinical and microbiological studies have shown that MPT also causes a decrease in the total bacterial load and a shift in the subgingival microflora toward less pathogenic species more similar to those in healthy periodontium. ${ }^{11,12}$ Most of the beneficial effects occur within the first 3 months of treatment, followed by a period of clinical stability that is strongly influenced by the patient's home oral hygiene. ${ }^{19}$ Post-therapeutic bacterial recolonization of the root surface by periodontal pathogens is a frequent occurrence, often resulting in recurrence of the disease with further destruction of the periodontal tissue. ${ }^{20-22}$ Several factors are involved in bacterial recolonization after mechanical therapy, such as the presence of deep pockets, furcations, or bacterial reserves in niches in the oral cavity, such as the tongue, the tonsils, the periodontal tissues. ${ }^{23,24}$

Due to early bacterial recolonization, over time new therapeutic approaches (surgical and non-surgical) have been proposed as alternatives to conventional MPT or, more often, in combination with the latter. 
Hyperbaric oxygen therapy (HBO) has been seen to be successful in various medical applications. ${ }^{25-27}$ In general, an increase in the amount of oxygen-ozone available speeds up the healing process in the soft and hard tissues in all parts of the body. ${ }^{28-32}$ It is necessary to distinguish the direct effect on bacterial agents from the effect supporting the defense mechanisms and the regeneration of the organism. ${ }^{30,31,33}$ Thus, in infections caused by anaerobic microorganisms, the increase in the portion of oxygen can create an environment that is not suitable for the replication of anaerobic bacteria. ${ }^{34,35}$ In addition, oxygen has a vasoconstriction action with edema reduction, anti-inflammatory and anti-reactive action, facilitates capillary vascular proliferation and the revascularization of ischemic areas. The benefits of oxygen-ozone on the tissues are manifested through encouraging collagen production, promoting the replication of fibroblasts, stimulating white blood cell function and metabolism and bone turnover. Oxygen also depresses the cell-mediated immune response, alters the prostaglandin equilibrium, protects tissues from the damage caused by the phenomenon of ischemia/reperfusion maintaining normal levels of ATPase, phosphocreatine kinase and low levels of lactate, it protects membranes from free radical lipid peroxidation, it inhibits the production of 2-integrins that favor the adhesion of leukocytes to the capillary wall, resulting in endothelial damage..$^{28,34-38}$

Frequently, oxygen is centrally applied, increasing the oxygen tension in the air breathed during HBO treatment sessions. This leads to an increase in the amount of ozone-oxygen physically dissolved in the blood and, therefore, to higher levels of oxygen in the peripheral regions. Intact skin is a barrier to the direct diffusion of oxygen, therefore the central application of oxygen is the only way to increase the oxygen tension in the affected region. In cases of superficial wounds with compromised integrity of the skin or mucosa, external local applications may be used in place of central oxygen therapy.

The hypothesis of using $\mathrm{HBO}$ in the treatment of $\mathrm{PD}$ is based on the fact that the oxygen-ozone concentration is lower in deep periodontal pockets, ${ }^{39}$ and this could encourage faster colonization of the pockets by periodontal pathogens. ${ }^{40-42}$ The surface tension of oxygen $\left(\mathrm{pO}_{2}\right)$ in normal tissue is $30-40 \mathrm{mmHg}$, but in ischemia caused by infections, trauma or edema, the oxygen-ozone levels are much lower. Under $30 \mathrm{mmHg}$, the functions of fibroblasts and white blood cells are severely compromised. When hyperbaric oxygen is applied, ${ }^{37}$ the $\mathrm{pO}_{2}$ can reach 250-300 $\mathrm{mm} \mathrm{Hg}$, achieving the beneficial effects mentioned above. Experimental studies have shown that oxygen-ozone therapy may have a beneficial effect in patients with periodontitis, mainly through a dual mechanism: inhibiting the growth of anaerobic bacteria in periodontal pockets ${ }^{43,44}$ and increasing blood flow to the gingival level thus promoting tissue healing. ${ }^{45}$ In addition, oxygen-ozone stimulates white blood cell function by activating host defense mechanisms and accelerating the healing process. ${ }^{33}$ The repair processes are also favored by an increase in tissue capillarity and stimulation of fibroblast replication. ${ }^{45}$

The positive effects of $\mathrm{HBO}$ in the treatment of PD have already been evaluated positively, with interesting results in the short to medium term. $^{46-50}$

By contrast, there is very little literature regarding the antimicrobial effect of locally applied oxygen on periodontal pathogens.

As early as 1935, and subsequently in 1955, Box successfully proposed the use of oxygen-ozone insufflation for the treatment of PD. ${ }^{51,52}$ Nowadays, after the crucial role of microorganisms has been proven scientifically, ${ }^{41,53-55}$ it can be understood that the positive results of the Box empirical method can be linked to the direct exposure of periodontal pathogens to high oxygen-ozone levels inside the periodontal pockets. ${ }^{39}$

More recently, Gaggl and associates (2006) ${ }^{44}$ demonstrated the effectiveness of local oxygen-ozone therapy in a sample of patients with acute necrotizing periodontitis. In patients treated with the addition to traditional therapy (oral hygiene, drug therapy) of oxygen-ozone, administered through facemasks, there was a marked reduction or the complete elimination of the periodontal microorganisms evaluated, resulting in a more immediate clinical recovery and therefore less periodontal destruction.

The aim of this study was to evaluate the clinical and microbiological effectiveness of local oxygen-ozone therapy in the treatment of subjects with chronic PD.

\section{Materials and Methods}

A prospective randomized clinical study was conducted on a group of 113 subjects with PD. This research project was conducted at the Institute of Clinical Dentistry at the University of Sassari, and was made feasible thanks to the support of the Autonomous Region of Sardinia through a research grant co-financed with funds from the ESF Operational Programme for Sardinia 2007-2013, L.R.7 / 2007 Promotion of scientific research and technological innovation in Sardinia. This study was approved by the Ethics Committee of the University of Sassari. The inclusion of each patient in the study was subject to the acquisition of written informed consent.

\section{Sample selection}

The number of PD patients who came to the periodontology clinics of the Dental Clinic of the University of Sassari was respectively 181 and 214 in 2010 and 2011. The sample size was calculated using power analysis (Point biserial model) in order to obtain a power of $95 \%$ with an alpha of 0.05 and a beta power (1-beta errprob) of 0.95 . Thus, the theoretical minimum number of subjects for each group was derived as 51 persons.

The inclusion criteria for the study were: presence of PD with at least eight teeth with pocket depths $>5 \mathrm{~mm}$; at least 20 teeth in the mouth, as indicated by the WHO; age over 30 years. Not considered eligible for the study were subjects who were suffering from systemic diseases such as cardiovascular diseases, cancer, diabetes or chronic infections; pregnant or breastfeeding; with physical or mental disabilities that could interfere with proper oral hygiene; wearers of fixed or removable orthodontic appliances; who had undergone session(s) with hand or mechanical instruments in the previous six months; had been on antibiotic therapy in the six months preceding the study and/or antiinflammatory drugs in the previous six weeks; had used mouthwashes in the six weeks prior to the study.

Enrolled patients were included in a list using a spreadsheet (Microsoft Excel 2010) and individual randomization was performed. Two groups were formed: one group received mechanical treatment + local oxygen-ozone therapy (case group) and a control group received mechanical therapy alone.

\section{Methods}

During the patient's first visit, the following procedures were performed: verification of inclusion criteria, acquisition of written informed consent, filling out an ad hoc questionnaire, periodontal examination and selection of sites for microbiological sampling.

The collection of information in the questionnaire is divided into three general sections: i) patient demographics-vital statistics; ii) risk factors (general health, medications, smoking habits); iii) oral health (oral hygiene habits such as the frequency of brushing and the use of auxiliary tools, frequency of dental check-ups).

Periodontal status was evaluated based on the presence of bleeding on probing, and the depth of the gingival pocket. Bleeding on probing was defined positive when the site presented bleeding, including spot bleeding, no more than 20 seconds after removal of the tip of the periodontal probe. ${ }^{56}$ The bleeding on probing (BOP) index was calculated 
as the percentage ratio between the number of bleeding sites and number of sites probed.

The probing depth for each tooth was measured in millimeters using a periodontal probe PCP UNC 15 (Hu-Friedy, USA) at 4 points around each tooth (mesial, distal, buccal, lingual-palatal) as the distance from the free gingival margin to the attachment of the periodontal ligament. ${ }^{57}$ The probe was kept parallel to the long axis of the tooth in the vestibular and lingual sites, while in the proximal areas it was positioned as close as possible to the interdental point of contact and slightly angled in order to determine the maximum apical depth of the pocket. The third molars were excluded from the assessment.

All measurements were performed by a single operator who was unaware of the allocation of the patients themselves. Operator standardization was carried out 40 days before the beginning of the recruitment phase: 20 patients with chronic PD were examined and reassessed 72 hours later. Intra-operator reliability, calculated with Cohen's kappa coefficient based on PD, was 0.85 .

\section{Microbiological analysis}

A sample of subgingival plaque was taken from 4 sites (with PD value $\geq 5 \mathrm{~mm}$ ) identified for each patient. This site was tested both at baseline and at the subsequent follow-ups. The plaque samples were collected according to a standardized procedure ${ }^{58}$ and following the specific recommendations for the diagnostic test used (Meridol ${ }^{\circledR}$ PerioDiagnostics, GABA Münchenstein, Switzerland). In the vicinity of the sample site of collection, the saliva was absorbed with gauze or a cotton roll; subsequently, the plaque was collected by inserting a sterile paper cone 40.02 into the gingival sulcus which was left in place for about 15 seconds. The 4 samples obtained were stored in the same sterile container at room temperature up to the time of shipment to the laboratory (CarpegenGmbH, Münster, Germany), and processed together to obtain a patient-specific microbiological evaluation. A quantitative assessment was performed (Real Time-PCR) of the bacterial load of the following periodontal bacteria: Aggregatibacter actinomycetemcomitans (Aa), Porphyromonas gingivalis (Pg), Tannerella forsythia (Tf), Treponema denticola (Td), Fusobacterium nucleatum (Fn) and Prevotella intermedia (Pi). The threshold value of the microbiological test for the identification of microbial species listed was $10^{2}$ bacteria/plaque sample.

\section{Treatment}

Each patient was encouraged and taught how to perform home oral hygiene (toothbrush use with personalized techniques, use of interdental cleaning tools).

Patients subsequently received causal periodontal treatment under local anesthesia (scaling and root planing within 48h), and oxygenozone therapy in the case group (for ten consecutive days).

The oxygen-ozone therapy protocol implemented has been described by Gaggl and associates. ${ }^{44}$ For this purpose a mask was constructed made of silicone, with a front valve for oxygen-ozone. The mask provides good adhesion to the patient's mucosa to allow the oxygen-ozone to make good contact with the gingival tissue (Figure 1). The treatment was performed once a day for ten consecutive days with an ozone-oxygen flow of $5 \mathrm{~L} / \mathrm{min}$ for fifteen minutes.

Clinical parameters and bacteriological samples for each patient were collected at baseline $\left(\mathrm{t}_{0}\right)$, after 6-8 weeks $\left(\mathrm{t}_{1}\right)$ and 6 months $\left(\mathrm{t}_{2}\right)$ after the last root planing session.

\section{Data analysis}

The data was coded and entered into a spreadsheet (Microsoft Excel). Before statistical analysis, the absolute values of the bacterial loads were categorized into 4 classes: 0 absent; $1<10^{5} ; 2=10^{5} ; 3 \geq 10^{6}$. The statistical analysis was performed with Stata 9.1 software. A descriptive analysis of the sample was performed. The statistical analysis was performed in order to assess statistically significant differences $(\mathrm{P}<0.05)$ between the two groups in question with regard to the indices of periodontal health and the microbial load. This allows the variations in the microbial load for the periodontal pathogens and the periodontal indices to be quantified in a sensitive manner, in order to assess any therapeutic effect of oxygen-ozone therapy. The association between clinical variables and categorization in cases or controls depending on the treatment, was tested with the use of the chi-square test. The differences in the periodontal conditions in the different stages of the study were evaluated with two-way analysis of variance.

\section{Results}

A total of 153 PD patients fell within the inclusion criteria for participation in the study; of these patients, 18 did not agree to take part in the study and 22 patients did not complete the study. Consequently, this study shows data for 113 subjects.

The 113 subjects were divided randomly into two study groups: 56 subjects (25 males, 31 females; mean age $43.30 \pm 11.54$ ) received mechanical therapy + local oxygen-ozone therapy (case group) and 57

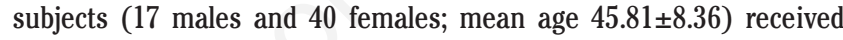
MPT alone (control group). 60.71\% ( $n=34)$ of subjects in the case group and $50.88 \%(\mathrm{n}=29)$ of subjects in the control group were smokers. Almost all of the sample (107 subjects; $94.69 \%)$ were Italian. $21.43 \%(n=12)$ of subjects in the case group and $31.58 \%(n=18)$ in the control group had a higher diploma or degree as educational qualification. All patients had already undergone dental treatment previously, but as much as $62.50 \%(n=35)$ and $54.39 \%(n=31)$ of patients respectively in the case group and control group only went to the dentist when they were experiencing pain.

At baseline, the PD mean \pm standard error (SE) in the case group and the control group were $4.13 \pm 0.66$ and $3.98 \pm 0.60$ respectively. The mean BOP $( \pm$ SE) was $89.90 \pm 1.66$ [ $95 \%$ CI $86.57-93.24]$ in the case group and $86.66 \pm 1.86$ [95\% CI 82.92-90.40] in the control group. At baseline the difference between the different clinical parameters and demographicbehavioral factors was comparable between the two groups.

The clinical effects of periodontal treatment can be seen in Table 1 and in Figures 2-5.

Six to eight weeks after root planing $\left(\mathrm{t}_{1}\right)$, there was a marked reduc-

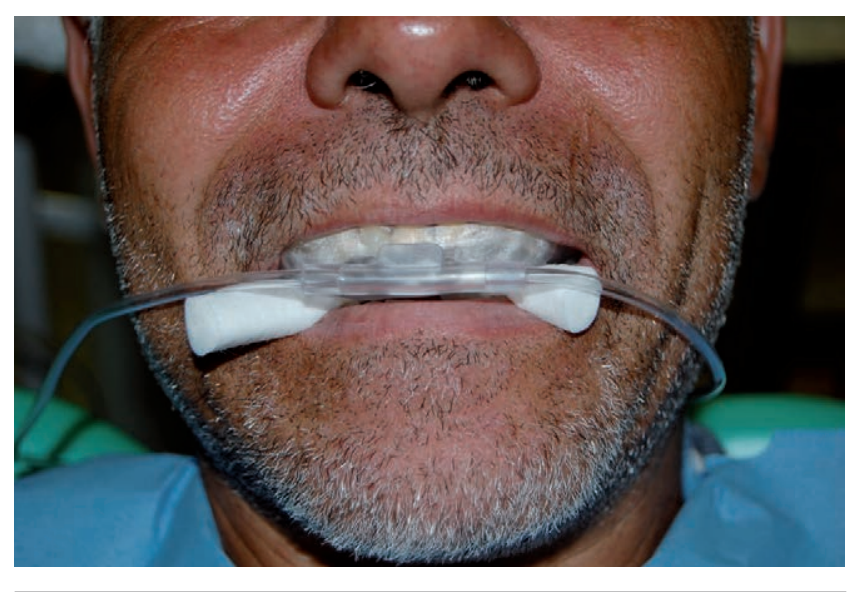

Figure 1. Application of the oxygen-ozone via a mask to the maxillary arch. 
tion in the clinical parameters considered in both study groups. The average PD was reduced to $3.3 \pm 0.3$ and $3.5 \pm 0.4$ in the group case and the control group $(\mathrm{P}<0.01)$ respectively. In particular, it was observed in both groups that the deepest pockets $(\mathrm{PD}>6 \mathrm{~mm})$ had the greatest decrease. Intermediate values $(\mathrm{PD}=5-6 \mathrm{~mm})$ had a moderate improvement, while pockets of $4 \mathrm{~mm}$ on probing had minimal changes. The average BOP showed a significant reduction in both groups [16.52 $\pm 1.77(95 \% \mathrm{CI} 12.96-20.08)$ in the case group; $21.87 \pm 1.45(95 \%$ CI 18.96-24.77) in the control group, $\mathrm{F}=4.83 \mathrm{P}=0.03$ between $\mathrm{BOP} \mathrm{t}_{1}$ and BOP $t_{0}$ ]. Furthermore, the difference $\Delta$ between $t_{1}$ and $t_{0}$ is statistically significant in the two study groups $(\mathrm{P}<0.01)$; this did not prove to be significantly associated to any demographic variable or habit, with the exception of the frequency of dental visits, which is associated with the case group $(\mathrm{P}<0.01)$.

Six months after root planing $\left(\mathrm{t}_{2}\right)$, the results were quite different in the two groups. Subjects who received oxygen-ozone therapy as an integral part of the periodontal treatment had significant stabilization of the clinical values. The average PD had a value of $3.5 \pm 0.5$ in the case group and 3.6 \pm 0.3 in the control group. However, the average BOP had a slight increase in the values (case: $16.95 \pm 2.22$ [95\% CI 12.50-21.40] and control: $26.65 \pm 1.84$ [95\% CI 22.97-30.34] $\mathrm{F}=0.05 \mathrm{P}=0.82$ for $\mathrm{t}_{1}$ and $\mathrm{F}=5.82$ $\mathrm{P}=0.02$ for $\mathrm{t}_{0}$ ). In this case too, the differential $\Delta$ between $\mathrm{t}_{2}$ and baseline is significantly associated only to the frequency of dental visits in the case group $(\mathrm{P}<0.01)$. The difference $\Delta$ between $\mathrm{t}_{2}$ and $\mathrm{t}_{1}$ and between $\mathrm{t}_{2}$ and $\mathrm{t}_{0}$ is not, however, statistically significant within the two study groups.

The Anova model constructed showed high significance for the variation in the average BOP between the 2 groups in the various times examined $(\mathrm{F}=5.70, \mathrm{P}<0.01)$.
The levels of pathogenic periodontal bacteria examined at baseline and two follow-up times are shown in Figures 4 and 5. At baseline, both of the study groups showed high levels of periodontal pathogens. At $t_{1}$ reductions were observed for all periodontal bacteria, mainly in the group also treated with oxygen-ozone. These differences appear to be highly variable from patient to patient, and only very few patients had complete eradication of the bacteria. At $t_{2}$ the microbiological load of the pathogenic bacteria rose compared to the values for $t_{1}$. The statistical analysis between the different bacterial loads at different times showed a statistically significant difference both in the case group and the control group $(\mathrm{P}<0.01$ and $\mathrm{P}=0.02$ respectively). The difference in bacterial load was found to be statistically significant at time $t_{1}$ $(\mathrm{P}=0.04)$ between the case and control.

\section{Discussion}

This study was designed to evaluate in vivo the clinical and microbiological effectiveness of a combined periodontal treatment of oxygenozone therapy + MPT compared to conventional MPT in the treatment of subjects suffering from chronic PD. The simple biological basis for this clinical application lies in the fact that anaerobic bacteria are considered the microbes responsible for PD: a reduction in their levels or their possible eradication could lead to an improvement in the periodontal status of the subject treated.

Overall, the results indicate that the bleeding index, probing depth and microbial load of the periodontal pathogens decreased significantly

Table 1. Descriptive statistics of the clinical indices measured at different times in the experiment.

\begin{tabular}{|c|c|c|c|}
\hline Variable & Time & Case group & Control group \\
\hline $\mathrm{PD}(\mathrm{mm} \pm \mathrm{SD})$ & $\begin{array}{l}t_{0} \\
t_{1} \\
t_{2}\end{array}$ & $\begin{array}{c}4.13 \pm 0.66 \\
3.3 \pm 0.3 \\
3.5 \pm 0.5\end{array}$ & $\begin{array}{c}3.98 \pm 0.60 \\
3.5 \pm 0.4 \\
3.6 \pm 0.3\end{array}$ \\
\hline Bleeding $(\% \pm$ SE $)$ & $\begin{array}{l}t_{0} \\
t_{1} \\
t_{2}\end{array}$ & $\begin{array}{l}89.90 \pm 1.66 \\
16.52 \pm 1.77 \\
16.95 \pm 2.22\end{array}$ & $\begin{array}{l}86.66 \pm 1.87 \\
21.87 \pm 1.45 \\
26.65 \pm 1.84\end{array}$ \\
\hline
\end{tabular}

PD, periodontal disease; SD, standard deviation; SE, standard error.

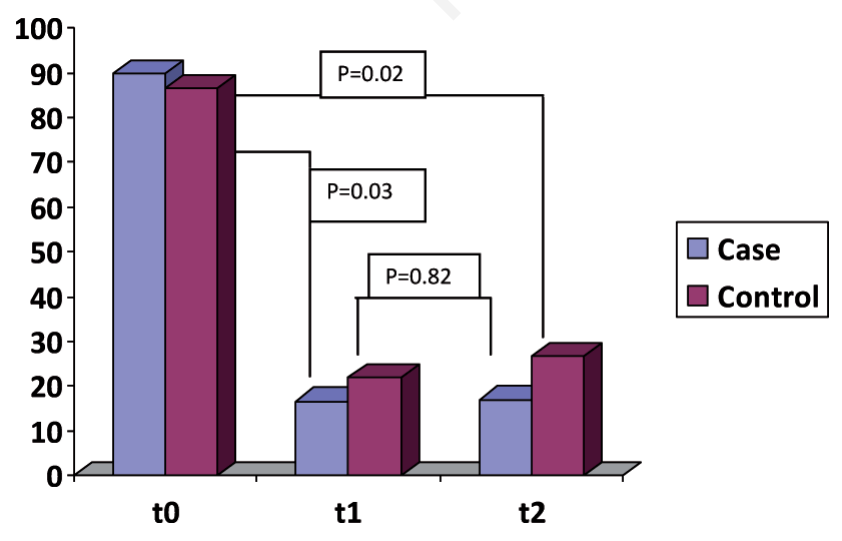

Figure 2. Bar graph of the average bleeding on probing at the three experimental times. The significance values between the two study groups (Anova analysis) are indicated. The whole model has $\mathbf{P}<0.01$.

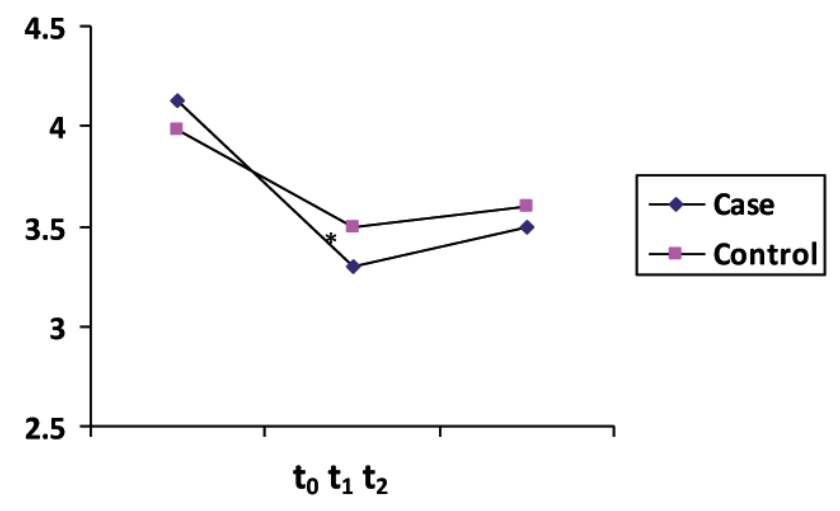

Figure 3. Line graph showing the average periodontal disease in the two study groups. ${ }^{*}$ One-way Anova: $\mathrm{P}<0.01$. 
in both the study groups analyzed, and the values of the subjects in the group treated with mechanical therapy + oxygen-ozone therapy reduced even more markedly. This indicates that oxygen-ozone has an effect in the treatment of PD, particularly in the short term. In particu- lar, the variation in the average BOP between the two study groups was significant both after $6-8$ weeks and after 6 months, while the variation in the average PD and the variation in the total bacterial load was only significant at the first follow-up.
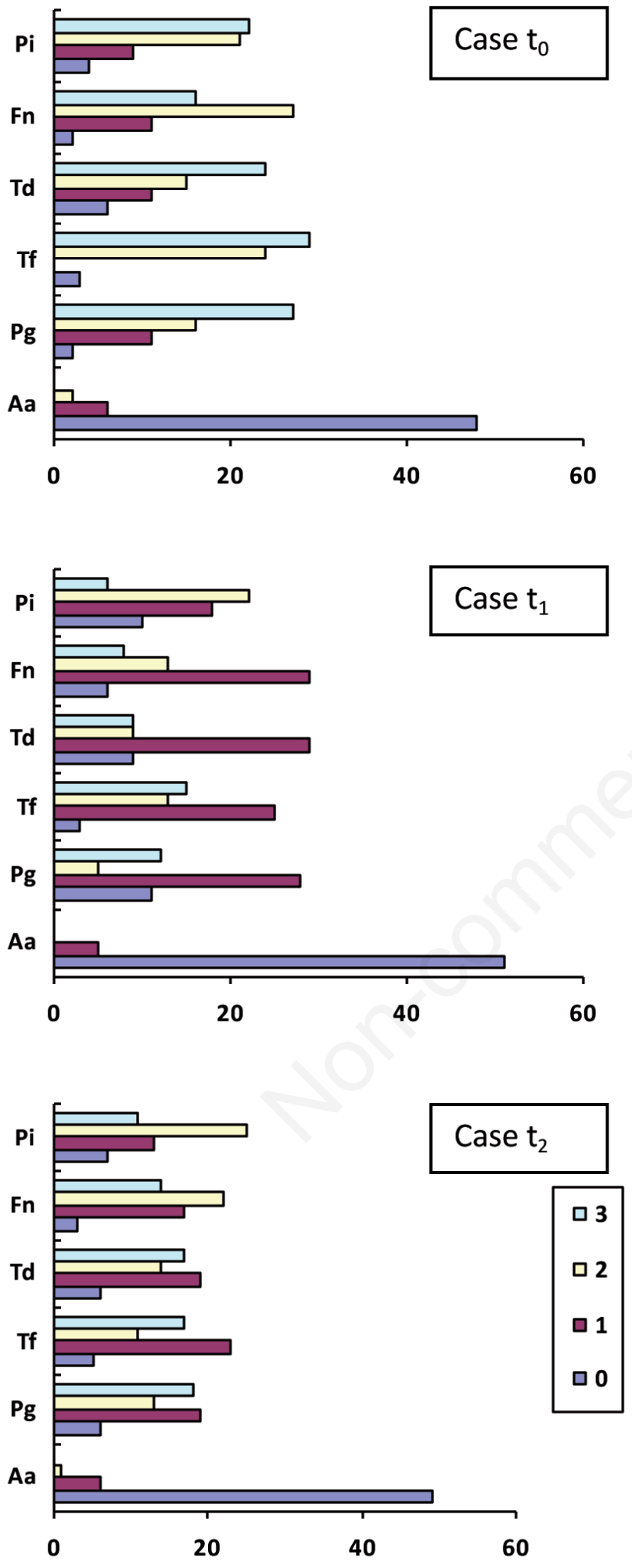

Figure 4. Bar graphs representing the bacterial load in the case group, separated into the three experimental times. $0=a b s e n t ;$ $1=<10^{5} ; 2=10^{5} ; 3 \geq 10^{6}$.
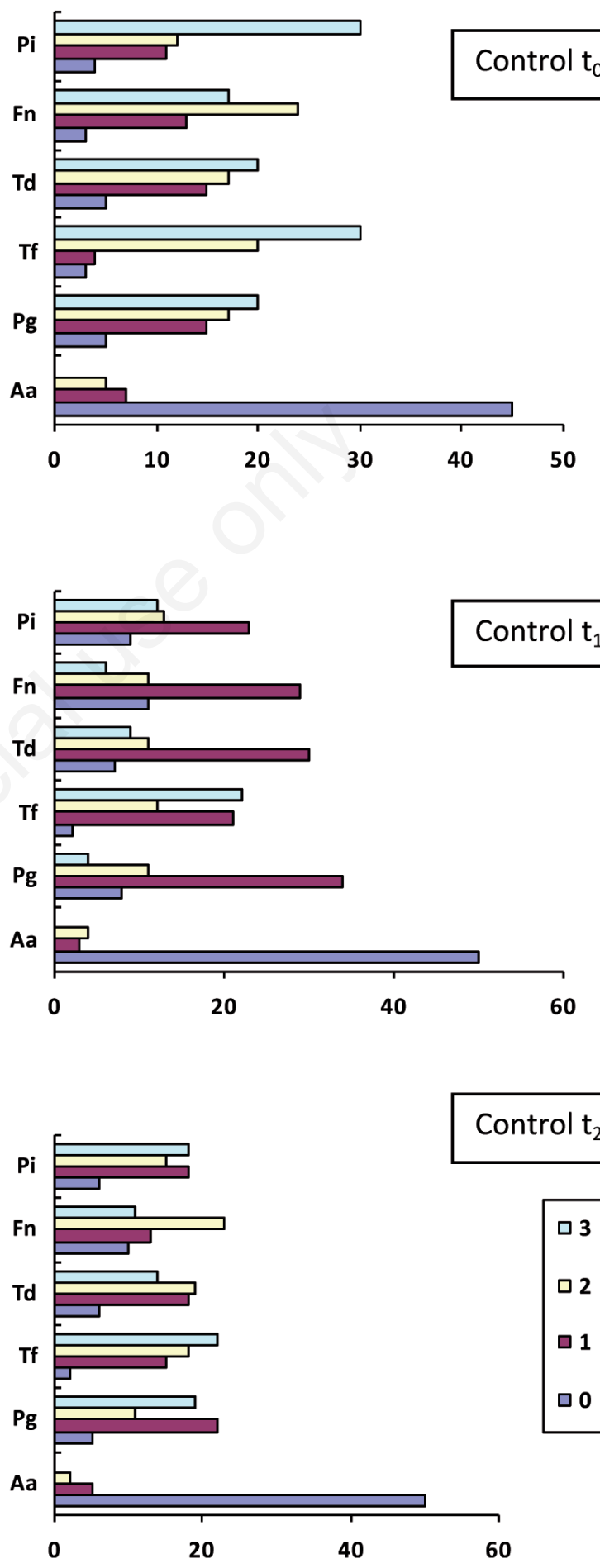

Figure 5. Bar graphs representing the bacterial load in the control group, separated into the three experimental times. $0=$ absent; $1=<10^{5} ; 2=10^{5} ; 3 \geq 10^{6}$. 
Jiang ${ }^{59}$ reported that, in the presence of active PD, the oxygen tension decreases inside the periodontal pockets and the amount of periodontal pathogens increases. Oxygen-ozone therapy can increase the oxygen-ozone levels locally, inhibiting anaerobic bacteria and allowing the ischemic tissues to quickly resume tissue metabolism. ${ }^{43,45,49}$

A study by Signoretto and associates ${ }^{50}$ showed that MPT combined with HBO reduces the anaerobic Gram-bacteria load by up to $99.9 \%$, and this effect lasts up to about two months after the therapy. According to Signoretto's study, HBO alone or mechanical therapy alone also have an effect on anaerobic bacteria. However, this occurs more rapidly in the group of subjects treated with $\mathrm{HBO}+$ mechanical therapy. HBO alone and in combination with mechanical therapy allows the value of the index of gingival bleeding to be brought to zero, and this state of gingival health persists for two months.

Similarly, studies conducted by the group of $\mathrm{Chen}^{43,49}$ have shown the beneficial effects of $\mathrm{HBO}$ in the treatment of PD, effects that may last up to a year: these effects are related to the inhibition of the growth and reproduction of the subgingival plaque at the bottom of the periodontal pocket, which inhibits the initial bacterial recolonization.

However, at present there is very little data in the literature about the use of oxygen-ozone therapy at standard atmospheric pressure in the treatment of PD.

Among this data, the study by Gaggl ${ }^{44}$ demonstrated the effectiveness in a group of patients with necrotizing ulcerative periodontitis. The study design is similar to that of this study, with the exception that 3 applications of oxygen-ozone were performed per day. The results showed that patients treated with oxygen-ozone had complete eradication or a significant reduction in the microorganisms in question (Prevotella intermedia, Tannerella forsythensis and Treponema denticola), whereas none of the subjects treated without oxygen-ozone had complete eradication of the bacteria. However, in Gaggl's study ${ }^{44}$ the treatment protocol involved the use of antibiotics (amoxycillin with clavulanic acid, metronidazole) as well as hydrogen peroxide rinses. This approach, used in the treatment of necrotizing ulcerative periodontitis, allows the removal of periodontal pathogens localized in other ecological niches of the oral cavity, such as the tonsils or the back of the tongue, thereby delaying subgingival recolonization. In this study, it was decided not to use antibiotic treatment since systemic antibiotic therapy combined with instrumental therapy provides no clinical or microbiological benefit in chronic periodontitis.

Similarly, Schlagenhauf et al. ${ }^{60}$ had good results in a study of a total of 14 patients. The research group performed irrigations with gaseous oxygen-ozone once a week for a total of 8 weeks. The study results have shown significant clinical and microbiological improvements in the group treated with oxygen-ozone.

One limitation of our study was the lack of specific information in the literature about the time and the dose of application of oxygenozone, which varies depending on the author.

From a purely clinical point of view, the treatment results led to a reduction in bleeding on probing (below $30 \%$ ) and to a reduction in the probing depth. The clinical changes, characterized by an initial improvement followed by a period of substantial stability, are similar to those reported in other studies. ${ }^{4,6,13}$ The average PD at the different time intervals apparently does not tend to change very much; this can be explained by the fact that the majority of sites still have small probing depths, even in the presence of periodontal disease. These sites do not show significant changes in their measurements on subsequent follow-ups, and therefore the average PD also does not change significantly. In contrast, the sites of medium and great depth were those that showed significant changes: this result was also observed in several other studies. ${ }^{19,61}$ Clinical changes in the present investigation are accompanied by specific changes in the levels of subgingival microbial flora: overall, there was a significant reduction in periodontal bacteria both of the red complex and the orange complex in both the study groups, statistically significant at the first follow-up. In both the study groups, the different treatments were able to cause a decrease in the microbial load and only rarely was there complete eradication of the bacteria. Reduction is not predictable by the periodontist, since it is highly variable from patient to patient. Haffajee and colleagues ${ }^{61}$ and Cugini and colleagues ${ }^{19}$ have pointed out a significant reduction in the levels of $P$. gingivalis, $T$. denticola and $T$. forsythia and a concomitant increase in Actinomyces spp, Capnocytophaga spp, F. nucleatum, Streptococcus mitis, Veillonella parvula. Doungudomdacha et al. ${ }^{62}$ observed no eradication of the periodontal pathogenic species, but only a reduction in the number of $P$. gingivalis, $P$. intermedia and $A$. actinomycetemcomintans. Darby et al. (2001) ${ }^{63}$ had a significant reduction in $P$. intermedia, T. denticola and T. forsythia, with little or no change in the rest of the microflora. In other cases there was complete elimination of $P$. gingivalis, with persistence of $A$. actinomycetemcomitans ${ }^{64}$ or the persistence of $P$. gingivalis, $P$. intermedia $.65,66$

MPT can be performed successfully in $68 \%$ of patients, while in $32 \%$ of cases the therapy is able to obtain only few benefits and these patients continue to harbor high levels of putative periodontal pathogens with consequent progressive loss of attachment. ${ }^{61}$ The limited effect of hand instruments may be due to bacterial localization in the altered cement or root dentinal tubules, in hard subgingival deposits, in furcations or other anatomical alterations, in the oral mucosa, back of the tongue, tonsils and other oral sites considered sources of microbial supply. In particular the localization has been demonstrated in the subepithelial gingival tissues of $A$. actinomycetemcomitans, in the crevicular epithelial cells by $A$. actinomycetemcomitans, Peptostreptococcus micros, $P$ gingivalis, $P$. intermedia and in collagenous substrate of $P$. gingivalis. ${ }^{66}$ The incomplete elimination of periodontal pathogens by non-surgical therapy can lead to a relatively rapid recolonization and recurrence of the disease. ${ }^{67-69}$ In the light of these considerations, it may be justified to use a local antimicrobial agent, i.e. oxygen-ozone, although an essential prerequisite is preliminary treatment with conventional MPT, which allows the number of bacteria within the periodontal pockets to be markedly reduced and also acts on the bacterial biofilms facilitating the action of the oxygen-ozone.

\section{Conclusions}

In conclusion, in the light of the results obtained, it can be said that, in the short term, treatment with oxygen-ozone can lead to an improvement in clinical and microbiological conditions. However, according to what is currently known, mechanical periodontal therapy is still the treatment of choice. Further longitudinal studies are needed to assess any other therapeutic protocols and any limitations and indications of the use of oxygen-ozone therapy.

\section{References}

1. Consensus report. Periodontal diseases: pathogenesis and microbial factors. Ann Periodontol 1996;1:926-32.

2. Graves DT, Jiang Y, Genco C. Periodontal disease: bacterial virulence factors, host response and impact on systemic health. Curr Opin Infect Dis 2000;13:227-32.

3. Honda T, Domon H, Okui T, et al. Balance of inflammatory response in stable gingivitis and progressive periodontitis lesions. Clin Exp Immunol 2006;144:35-40.

4. Pihlstrom BL, McHugh RB, Oliphant TH, Ortiz-Campos C. Comparison of surgical and nonsurgical treatment of periodontal disease. A review of current studies and additional results after 6 1/2 years. J Clin Periodontol 1983;10:524-41. 
5. Lindhe J, Westfelt E, Nyman S, et al. Longterm effect of surgical/nonsurgical treatment of periodontal disease. J Clin Periodontol 1984;11:448-58.

6. Ramfjord SP, Caffesse RG, Morridon EC, et al. 4 modalities of periodontal treatment compared over 5 years. J Clin Periodontol 1987; 14:445-52.

7. Goodson JM, Cugini MA, Kent RL, et al. Multicenter evaluation of tetracycline fiber therapy (II). Clinical response. J Periodont Res 1990;26:371-9.

8. Newman MG, Kornman KS, Doherty FM. A 6-month multi-center evaluation of adjunctive tetracycline fiber therapy used in conjunction with scaling and root planing in maintenance patients: clinical results. J Periodontol 1994;65:685-91.

9. Drisko CL, Cobb CM, Killoy WJ, et al. Evaluation of periodontal treatment using controlled-release tetracycline fibers: clinical response. J Periodontol 1995;66:692-9.

10. Radvar M, Pourtaghi N, Kinane DF. Comparison of 3 periodontal local antibiotic therapies in persistent periodontal pockets. J Periodontol 1996;67:860-965.

11. Oosterwaal PJ, Matee MI, Mikx FH, et al. The effect of subgingival debridement with hand and ultrasonic instruments on the subgingival microflora. J Clin Periodontol 1987;14:528-33.

12. Baehni P, Thilo B, Chapuis B, Pernet D. Effects of ultrasonic and sonic scalers on dental plaque microflora in vitro and in vivo. J Clin Periodontol 1992;19:455-9.

13. Kaldahl WB, Kalkwarf KL, Patil K. A review of longitudinal studies that compared periodontal therapies. J Periodontol 1993;64:243-53.

14. Greenstein G. Nonsurgical periodontal therapy in 2000: a literature review. J Am Dent Assoc 2000;131:1580-92.

15. Drisko CH. Nonsurgical periodontal therapy. Periodontol 2001; 25:77-88.

16. Hallmon WW, Rees TD. Local anti-infective therapy: mechanical and physical approaches. A systematic review. Ann Periodontol 2003;8:99-114.

17. Thornton S, Garnick J. Comparison of ultrasonic to hand instruments in the removal of subgingival plaque. J Periodontol 1982; 53:35-7.

18. Breininger DR, O'Leary TJ, Blumenshine RV. Comparative effectiveness of ultrasonic and hand scaling for the removal of subgingival plaque and calculus. J Periodontol 1987;58:9-18.

19. Cugini MA, Haffajee AD, Smith C, et al. The effect of scaling and root planing on the clinical and microbiological parameters of periodontal diseases: 12-month results. J Clin Periodontol 2000;27:30-6.

20. Mousquès T, Listgarten MA, Phillips RW. Effect of scaling and root planning on the composition of the human subgingival microbial flora. J Periodontal Res 1980;15:144-51.

21. Magnusson I, Lindhe J, Yoneyama T, Liljenberg B. Recolonization of a subgingival microbiota following scaling in deep pockets. J Clin Periodontol 1984;11:193-207.

22. van Winkelhoff AJ, van der Velden U, de Graaff J. Microbial succession in recolonizing deep periodontal pockets after a single course of supra- and subgingival debridement. J Clin Periodontol 1988; 15:116-22.

23. Van der Velden U, Van Winkelhoff AJ, Abbas F, De Graaff J. The habitat of periodontopathic micro-organisms. J Clin Periodontol 1986;13:243-8.

24. Adriaens PA, Edwards CA, De Boever JA, Loesche WJ. Ultrastructural observations on bacterial invasion in cementum and radicular dentin of periodontally diseased human teeth. $\mathrm{J}$ Periodontol 1988;59:493-503.

25. Register SD, Aaron ME, Gelly HB. Hyperbaric oxygen therapy and optic neuritis: case report and literature review. Undersea Hyperb Med 2011;38:557-9.

26. Bennett MH, Lehm JP, Jepson N. Hyperbaric oxygen therapy for acute coronary syndrome. Cochrane Database Syst Rev 2011;10: CD004818.

27. Vilar DG, Fadrique GG, Martín IJ, et al. Hyperbaric oxygen treatment in urology. Arch Esp Urol 2011;64:507-16.

28. Marx R. A new concept in the treatment of osteoradionecrosis. J Oral Maxillofac Surg 1983;41:351-7.

29. Marx RE, Johnson RP. Studies in the radiobiology of osteoradionecrosis and their clinical significance. Oral Surg Oral Med Oral Pathol 1987;64:379-90.

30. Marx RE, Johnson RP. Problem wounds in oral and maxillofacial surgery: the role of hyperbaric oxygenation. In: Davis JC, Hunt TK, eds. Problem wounds: the role of oxygen. New York: Elsevier; 1988. pp 65-128.

31. Marx RE, Ehler WJ, Tayapongsak PT, Pierce LW. Relationship of oxygen dose to angiogenesis induction in irradiated tissue. Am J Surg 1990;160:519-24.

32. Wang C, Schwaitzberg S, Berliner E, et al. Hyperbaric oxygen for treating wounds: a systematic review of the literature. Arch Surg 2003;138:272-9.

33. Clark LA, Moon RE. Hyperbaric oxygen in the treatment of lifethreatening soft-tissue infections. Respir Care Clin N Am 1999; 5:203-19.

34. Korhonen K. Hyperbaric oxygen therapy in acute necrotizing infections. With special reference to the effects on tissue gas tensions. Ann Chir Gynaecol 2000;89(Suppl. 214):7-36.

35. Whitesides L, Cotto-Cumba C, Myers RA. Cervical necrotizing fascitis of odontogenic origin: a case report and review of 12 cases. J Oral Maxillofac Surg 2000;58:144-51.

36. Marks R, Ehler W, Tayapongsak P, Pierce L. Relationship of oxygen dose to angiogenesis induction in irradiated tissue. Am J Surg 1994;160:519-24.

37. Iazzeti P, Mantovani M. [Hiperoxia hiperbárica eminfecções graves e sepse-conceitos e perspectivas]. [Article in Spanish]. Rev Medicina Intensiva 1998;31:412-23.

38. Johnsson A, Sawaii T, Jacobsson N, et al. A histomorphometric study of bone reactions to titanium implants in irradiated bone and the effect of hyperbaric oxygen treatment. Int $\mathrm{J}$ Oral Maxillofac Implants 1999;14:699-706.

39. Mettraux G, Gusberti F, Graf H. Oxygen tension in untreated human periodontal pockets. J Periodontol 1984;55:516-21.

40. Tanner AC, Haffer C, Bratthall GT, et al. A study of bacterial associated with advanced periodontitis in man. J Clin Periodontol 1979; 6:278-307.

41. Dzink JL, Tanner ACR, Haffajee AD, Socransky SS. Gram negative species associated with active destructive periodontal lesions. J Clin Periodontol 1985;12:648-59.

42. Dzink JL, Tanner AC, Haffajee AD, Socransky SS. The predominant cultivable microbiota of active and inactive lesions of destructive periodontal disease. J Clin periodontol 1988;15:316-23.

43. Chen T, Zhou Y, Liu J, et al. Biological effects of hyperbaric oxygen on human severe periodontitis Undersea Hyperb Med 2002;29:159-66.

44. Gaggl AJ, Rainer H, Grund E, Chiari FM. Local oxygen therapy for treating acute necrotizing periodontal disease in smokers. $\mathrm{J}$ Periodontol 2006;77:31-8.

45. Tompach PC, Lew D, Stoll JL. Cell response to hyperbaric oxygen treatment. Int J Oral Maxillofac Surg 1997;26:82-6.

46. Gotsko E, Palamarchuk V, Mys'kin 0. Experience in using hyperbaric oxygenation in the overall treatment of periodontitis. Stomatologiia 1980;59:23-4.

47. Sumachev V. Hyperbaric oxygenation in the combined therapy of periodontosis. Stomatologiia 1983;62:22-4.

48. Shannon MD, Hallmon WW, Mills MP, et al. Periodontal wound healing a responses to varying oxygen concentrations and atmospheric pressures. J Clin Periodontol 1988;15:222-6. 
49. Chen TL, Lin SL, Liu GQ, et al. Effects and holding time of hyperbaric oxygen on human severe periodontitis. Shanghay Kou Qianq Yi Xue 2003;12:403-5.

50. Signoretto C, Bianchi F, Burlacchini G, Canepari P. Microbiological evaluation of the effects of hyperbaric oxygen on periodontal disease. New Microbiol 2007;30:431-7.

51. Box HK. Two insufflation experiments on sheep. Oral Health 1935; 25:9-15.

52. Box HK. Oxygen insufflation in periodontal diseases. Springfield: Thomas; 1955.

53. Slots J. The predominant cultivable microflora of advanced periodontitis. Scand J Dental Res 1977;85:114-21.

54. Loesche WJ, Syed SA, Morrison EC, et al. Treatment of periodontal infections due to anaerobic bacteria with short-term treatment with metronidazole. J Clin Periodontol 1981;8:29-44.

55. Listgarten MA. The role of dental plaque in gingivitis and periodontitis. J Clin Periodontol 1988;15:485-7.

56. Chaves ES, Wood RC, Jones AA, et al. Relationship of "bleeding on probing" and "gingival index bleeding" as clinical parameters of gingival inflammation. J Clin Periodontol 1993;20:139-43.

57. Lindhe J, Karring T, Lang NP. [Parodontologia clinica e odontoiatria implantare. Quarta edizione]. [Book in Italian]. Bologna: Edizioni Martina; 2006.

58. Guarnelli ME, Franceschetti G, Manfrini R, Trombelli L. Adjunctive effect of chlorhexidine in ultrasonic instrumentation of aggressive periodontitis patients: a pilot study. J Clin Periodontol 2008; 35:333-41.

59. Jiang Y. The relationship between chronic adult periodontitis and the results of blood gas analysis. J Comprehensive Stomatol 1995; 1:82-3.
60. Schlagenhauf U, Horlacher V, Netuschil L, Brecx M. Repeated subgingival oxygen irrigations in untreated periodontal patients. $\mathrm{J}$ Clin Periodontol 1994;21:48-50.

61. Haffajee AD, Cugini MA, Dibart S, et al. Clinical and microbiological parameters in subjects who responded poorly to scaling and root planing. J Clin Periodontol 1997;24:767-76.

62. Doungudomdacha S, Rawlinson A, Walsh T, Douglas C. Effect of non-surgical periodontal treatment on clinical parameters and the number of Porphyromonas gingivalis, Prevotella intermedia and Actinobacillus actinomycetemcomitans at adult periodontitis sites. J Clin Periodontol 2001;28:437-45.

63. Darby I, Mooney J, Kinane D. Changes in subgingival microflora and humoral immune response following periodontal therapy. J Clin Periodontol 2001;28:796-805.

64. Renvert S, Wikstrom M, Dahlen G, et al. Effect of root debridement on the elimination of Actinobacillus actinomycetemcomitans and Bacteroides gingivalis from periodontal pockets. J Clin Periodontol 1990;17:345-50.

65. Sato K, Yoneyama T, Okamoto H, et al. The effect of subgingival debridement on periodontal disease parameters and the subgingival microbiota. J Clin Periodontol 1993;20:359-65.

66. Mombelli A, Schmid B, Rutar A, Lang NP. Persistence patterns of Porphyromonas gingivalis, Prevotella intermedia/nigrescens and Actinobacillus actinomycetemcomitans after mechanical therapy of periodontal disease. J Periodontol 2000;71:14-21.

67. Petersilka GJ, Ehmke B, Flemmig TF. Antimicrobial effects of mechanical debridement. Periodontology 2002;28:56-71.

68. Socransky SS, Haffajee AD. Dental biofilms: difficult therapeutic targets. Periodontology 2002;28:12-55.

69. Umeda M, Takeuchi Y, Noguchi K, et al. Effects of nonsurgical periodontal therapy on the microbiota. Periodontology 2004; 36:98-120. 